\title{
Reversion-inducing cysteine-rich protein with Kazal motifs gene expression and its clinical significance in peripheral T-cell lymphoma
}

\author{
XIA MAO, LONGLONG LIU, BING ZHANG and DONGHUA ZHANG \\ Department of Hematology, Tongji Hospital, Tongji Medical College, \\ Huazhong University of Science and Technology, Wuhan, Hubei 430030, P.R. China
}

Received December 13, 2012; Accepted April 12, 2013

DOI: $10.3892 / \mathrm{ol} .2013 .1306$

\begin{abstract}
The reversion-inducing cysteine-rich protein with Kazal motifs $(R E C K)$ gene was originally identified as a transformation suppressor gene that is widely expressed in normal tissues. In tumor tissues, RECK expression levels are significantly reduced, and the downregulation of $R E C K$ has been implicated in tumors that are more aggressive with a poor prognosis. In the present study, $R E C K$ expression in peripheral T-cell lymphoma (PTCL; $n=82$ ) was examined using immunohistochemistry, and its correlation with clinicopathological factors was analyzed. According to the proportion of positively-stained cells and the staining intensity (SI), the patients were categorized into RECK-negative or RECK-positive groups. $R E C K$ expression was observed in 30 of the 82 patients (36.6\%). The 3-year survival rate of the patients with $R E C K$-positive tumors $(65.5 \%)$ was significantly high compared with that of the patients with $R E C K$-negative tumors $(20.3 \%$; $\mathrm{P}=0.046)$. Reduced $R E C K$ expression was found to be significantly correlated with extranodal lymphomatous involvement $(\mathrm{P}=0.012)$. The survival analysis showed that $R E C K$-negative expression was an independent and significant factor for predicting a poor prognosis. RECK status is a useful prognostic factor for assessing the biological behavior in PTCL.
\end{abstract}

\section{Introduction}

The term peripheral T-cell lymphoma (PTCL) does not refer to the site of involvement, but to the immunophenotype of these tumors that derive from post-thymic (or mature) $\mathrm{T}$ cells at various steps of differentiation $(1,2)$. Since natural killer (NK) cells are closely associated with $\mathrm{T}$ cells, and share certain immunophenotypic and functional properties, mature T-cell

Correspondence to: Professor Donghua Zhang, Department of Hematology, Tongji Hospital, Tongji Medical College, Huazhong University of Science and Technology, 1095 Jiefang Road, Wuhan, Hubei 430030, P.R. China

E-mail: zdh62@yahoo.com.cn

Key words: reversion-inducing cysteine-rich protein with Kazal motifs, prognosis, peripheral T-cell lymphoma and NK-cell lymphomas are usually classed together $(1,2)$. PTCL comprises of a heterogeneous group of hematological tumors that the World Health Organization (WHO) classification subdivides into specified and unspecified (U) (3). These tumors constitute $\sim 12 \%$ of all lymphoid neoplasms $(4,5)$ and their incidence varies between countries and races, being higher in Japan and other Eastern areas for epidemiological reasons, including the presence of human T-lymphotropic virus 1 (HTLV-1) infections (6-8). These neoplasms often present at an advanced stage in middle-aged/elderly patients at diagnosis (9-11) and most commonly have an aggressive clinical course. Patients succumb rapidly despite prompt therapies. Relapse is common and the prognosis is poor. The rarity of these tumors means that additional studies are required to improve our understanding of their biology.

The reversion-inducing cysteine-rich protein with Kazal motifs (RECK) gene was originally isolated using cDNA expression cloning designed to locate transformation suppressor genes against activated ras oncogenes (12). The RECK gene is widely expressed in numerous normal tissues and non-neoplastic cell lines, but its expression is low or undetectable in oncogene-transformed fibroblasts or tumor-derived cell lines $(13,14)$. The $R E C K$ gene encodes a membrane-anchored glycoprotein that is a negative regulator of the matrix metalloproteinases (MMPs), including MMP-2, MMP-9 and MT1-MMP. The restoration of $R E C K$ expression in malignant cells reduces pro-matrix MMP-9 secretion and suppresses the ability to invade and metastasize, suggesting a role for $R E C K$ in the regulation of MMPs and tumor invasiveness (13). Numerous studies have reported that a lower expression of $R E C K$ is associated with a worse prognosis in a variety of cancers (15-19), but little is known with regard to the significance of RECK in PTCL.

Therefore, in the present study, the expression of $R E C K$ was analyzed in patients with PTCL and these data were compared with the clinical and pathological features to determine whether the expression of $R E C K$ is a predictor of the clinical behavior of PTCL.

\section{Materials and methods}

Patients and tumor samples. A total of 82 patients with PTCLs who were diagnosed between 2006 and 2010 at the Department 
of Pathology, Tongji Hospital (Wuhan, Hubei, China), were included in the present study. Approval for the study was obtained from the Medical Ethics Committee of the Tongji Hospital. The specimens and clinical data were collected subsequent to obtaining informed consent in accordance with the Declaration of Helsinki. Samples were obtained at the initial presentation of the patients, then fixed in formalin and embedded in paraffin. The tumor specimens that were analyzed were from biopsies performed prior to chemotherapy. The paraffin blocks were evaluated again to select a representative area. All cases were reviewed carefully and the pathological diagnosis of PTCL was made according to the WHO criteria for the classification of malignant lymphoma following precise immunohistochemical evaluation (20). The clinical features of age, gender, tumor stage, performance status, serum concentration of lactate dehydrogenase (LDH), extranodal lymphomatous involvement, the presence or absence of B symptoms and the International Prognostic Index (IPI) (21), treatment and follow-up were analyzed. The recorded sites of extranodal lymphomatous involvement included the gastrointestinal tract, liver, spleen, lungs, central nervous system and bone marrow (21).

Among the 82 selected patients, there were 55 males (67.1\%) and 27 females (32.9\%), with an average age of 42.2 years (range, 7-77 years). The histological subtypes were PTCL-not otherwise specified (PTCL-NOS; 28 cases), angioimmunoblastic T-cell lymphoma (22 cases), extranodal NK/T-cell lymphoma, nasal type (16 cases) and intestinal NK/T-cell lymphoma (16 cases). The tumor stages were classified as localized disease (stage 1 or 2 ) in 21 patients and advanced disease (stage 3 or 4 ) in 61 patients. There were 42 patients with extranodal lymphomatous involvement (Table I).

The follow-up duration was defined from the date of the initial presentation to the date of mortality or last follow-up. The median follow-up period was 24.1 months (range, 0-48 months). During the follow-up, 38 patients (46.3\%) were continuously disease-free, 40 patients $(48.8 \%)$ succumbed to the disease and four patients succumbed during chemotherapy.

Immunohistochemistry. RECK expression was determined using the streptavidin-peroxidase immunohistochemistry method. Serial 4- $\mu \mathrm{m}$ sections were cut from formalin-fixed, paraffin-embedded blocks and placed on polylysine-coated slides. The serial sections were deparaffinized in three changes of xylene, rehydrated in descending concentrations of ethanol and washed three times for $5 \mathrm{~min}$ each with double-distilled water. Following rehydration, the sections were placed in $0.01 \mathrm{M}$ sodium citrate buffer ( $\mathrm{pH} \mathrm{6.0)}$ for $10 \mathrm{~min}$ at $105^{\circ} \mathrm{C}$. Subsequent to being cooled to room temperature for $30 \mathrm{~min}$, the specimens were incubated for $30 \mathrm{~min}$ at room temperature in $0.3 \%$ hydrogen peroxide in methanol to inactivate endogenous peroxidase activity. The sections were then incubated for $30 \mathrm{~min}$ at $37^{\circ} \mathrm{C}$ with phosphate-buffered saline (PBS; $\mathrm{pH}$ 7.4) containing $5 \%$ bovine serum albumin (BSA; Merck, Darmstadt, Germany), followed by overnight incubation at $4^{\circ} \mathrm{C}$ with anti-RECK mouse monoclonal antibody (Clone 28; BD Transduction Laboratories, San Diego, CA, USA) diluted 1:200 in PBS containing 1\% BSA. The sections were washed three times for $5 \mathrm{~min}$ in PBS with Tween-20 and incubated for $1 \mathrm{~h}$ with biotinylated anti-mouse IgG secondary antibodies (Abcam, Cambridge, UK) diluted 1:300 in PBS containing 1\% BSA. Subsequent to rinsing, the immune complexes were visualized using the standard avidin-biotin-peroxidase complex (ABC) method and the sections were then counterstained with Mayer's hematoxylin and mounted. Positive controls guaranteed the persistent quality of the staining procedure. Negative control slides in the absence of primary antibody were included for each staining.

The expression of RECK was independently evaluated by two investigators without knowledge of the patients clinicopathological features. The data from the two investigators were averaged. An evaluation of the RECK staining reaction was performed in accordance with the immunoreactive score (IRS): IRS = SI (staining intensity) $\mathrm{x}$ PP (percentage of positive cells) (22). The proportional scoring categories of the positively-stained cells were as follows: i) 0 , no positivity; ii) $1+, \leq 10 \%$ positive tumor cells; iii) $2+, 11-50 \%$ positive tumor cells; iv) $3+, 50-80 \%$ positive tumor cells; and v) $4+,>80 \%$ positive tumor cells. The intensity of the RECK immunostaining was scored as follows: i) no staining, 0 ; ii) weak, 1+; iii) moderate, $2+$; and iv) intense, $3+$. For tumors that showed heterogeneous staining, the main pattern was taken into account for scoring. The IRS was calculated in $\geq 10$ areas at $x 400$ magnification and $\geq 1,000$ tumor cells were evaluated for each section. Tumor slices scoring at least three points were defined as positive, otherwise they were defined as negative (22).

Statistical analysis. The clinicopathological characteristics were compared with the expression levels of RECK using the $\chi^{2}$ test. The Kaplan-Meier method was used to analyze the post-operative survival rate, and the survival differences were analyzed using the log-rank test on the basis of the status of the RECK expression. Any factor affecting the prognosis in a univariate analysis was then estimated in a multivariate analysis using Cox's proportional hazard model with a forward conditional stepwise procedure to determine whether the factor was acting independently. All calculations were performed using SPSS version 13.0 (SPSS, Inc., Chicago, IL, USA) software and $\mathrm{P}<0.05$ was considered to indicate a statistically significant difference.

\section{Results}

Correlation of RECK protein expression with clinicopathological patient features. RECK staining was mainly observed in the cytoplasm and plasma membrane of the tumor cells, often in a granular pattern (Fig. 1). On the basis of multiplying the intensity and proportion scores of $R E C K$ in the tumors, 30 patients (36.6\%) were classified as $R E C K$-positive and $52(63.4 \%)$ as $R E C K$-negative. No correlation was revealed between the RECK status and the age, gender, subtype or tumor stage (Table I). RECK expression was inversely correlated with extranodal lymphomatous involvement ( $\mathrm{P}=0.012$; Fig. 2).

Correlation of RECK protein expression with prognostic factors. The univariate analyses of the prognostic factors demonstrated that the RECK expression, response to chemotherapy, IPI and tumor stage were significant prognostic factors. No correlations were evident between the prognosis and the age, gender or subtype. The 3-year survival rate of the RECK-positive patients was $65.5 \%$, which was significantly higher than that of the RECK-negative patients (20.3\%; 
Table I. Clinicopathological characteristics for RECK expression.

\begin{tabular}{|c|c|c|c|}
\hline \multirow[b]{2}{*}{ Variables } & \multicolumn{3}{|c|}{$R E C K$ expression } \\
\hline & Negative & Positive & P-value \\
\hline Patient Number & 52 & 30 & \\
\hline \multicolumn{4}{|l|}{ Age (years) } \\
\hline$>60$ & 12 & 11 & \multirow[t]{2}{*}{$\mathrm{NS}$} \\
\hline$<60$ & 40 & 19 & \\
\hline \multicolumn{4}{|l|}{ Gender } \\
\hline Male & 37 & 18 & \multirow[t]{2}{*}{$\mathrm{NS}$} \\
\hline Female & 15 & 12 & \\
\hline \multicolumn{4}{|l|}{ Histology } \\
\hline PTCL, unspecified & 21 & 7 & \multirow[t]{4}{*}{$\mathrm{NS}$} \\
\hline Angioimmunoblastic T-cell lymphoma & 7 & 15 & \\
\hline Extranodal NK/T-cell lymphoma, nasal & 13 & 3 & \\
\hline Intestinal NK/T-cell lymphoma & 11 & 5 & \\
\hline \multicolumn{4}{|l|}{ Clinical stage } \\
\hline 1,2 & 9 & 12 & \multirow[t]{2}{*}{ NS } \\
\hline 3,4 & 43 & 18 & \\
\hline \multicolumn{4}{|l|}{ Extranodal involvement } \\
\hline No & 14 & 26 & \multirow[t]{2}{*}{$0.012^{\mathrm{a}}$} \\
\hline Yes & 38 & 4 & \\
\hline \multicolumn{4}{|l|}{ B symptoms } \\
\hline No & 31 & 19 & \multirow[t]{2}{*}{$\mathrm{NS}$} \\
\hline Yes & 21 & 11 & \\
\hline \multicolumn{4}{|l|}{ Performance status } \\
\hline 0,1 & 42 & 18 & \multirow[t]{2}{*}{$\mathrm{NS}$} \\
\hline $2-4$ & 10 & 12 & \\
\hline \multicolumn{4}{|l|}{ LDH } \\
\hline Normal & 8 & 13 & \multirow[t]{2}{*}{$\mathrm{NS}$} \\
\hline Elevated & 44 & 17 & \\
\hline \multicolumn{4}{|l|}{ IPI } \\
\hline $0-2$ & 23 & 8 & \multirow[t]{2}{*}{ NS } \\
\hline $3-5$ & 29 & 22 & \\
\hline
\end{tabular}

${ }^{a} \mathrm{P}<0.05$. NS, not significant $(\mathrm{P}>0.05)$; LDH, lactate dehydrogenase; IPI, internal prognostic index; $R E C K$, reversion-inducing cysteine-rich protein with Kazal motifs; NK, natural killer; PTCL, peripheral T-cell lymphoma.
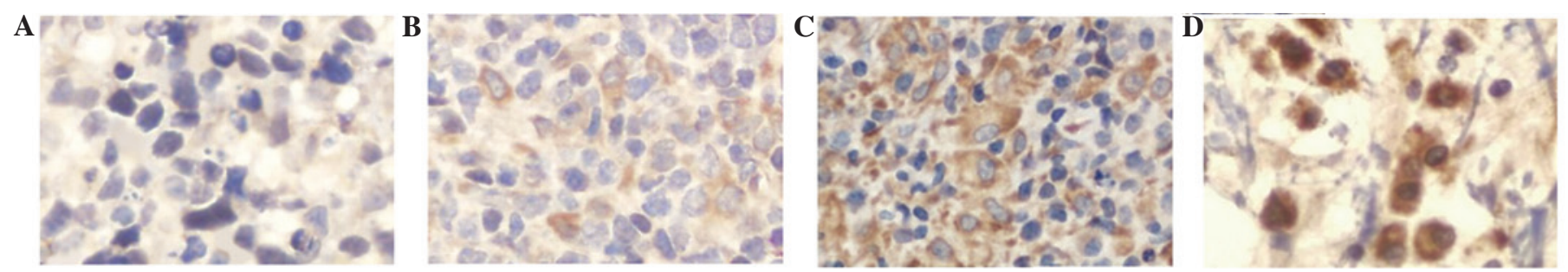

Figure 1. Immunohistochemical detection of reversion-inducing cysteine-rich protein with Kazal motifs (RECK) in peripheral T-cell lymphomas (PTCL). RECK immunoreactivity was found in the cytoplasm and plasma membrane of the tumor cells in a granular pattern. (A-D) Examples of lymphomas expressing different levels of RECK. (A) No detectable stain (intensity score 0 and proportion score 0 ). (B) Intensity score 1 and proportion score 1 . (C) Intensity score 2 and proportion score 2. (D) Intensity score 3 and proportion score 3. (Original magnification, x400; Mayer's hematoxylin stain).

$\mathrm{P}=0.046$; Fig. 3). A multivariate analysis confirmed that $R E C K$-positive protein expression was an independent and significant factor for predicting a favorable prognosis.

\section{Discussion}

PTCLs are a biologically diverse and uncommon group of 


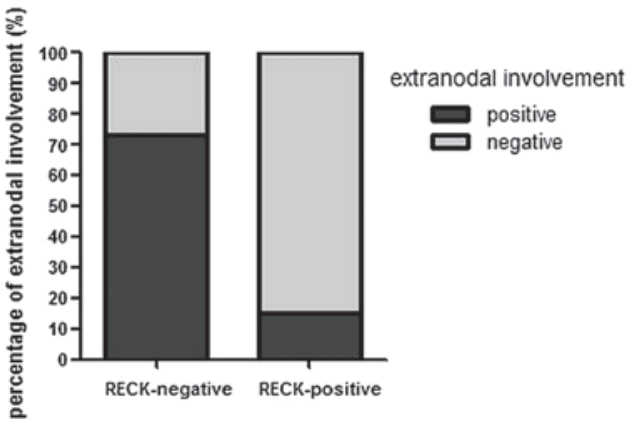

Figure 2. Correlation between reversion-inducing cysteine-rich protein with Kazal motifs (RECK) gene expression and extranodal lymphomatous involvement. Positive RECK expression was significantly associated with a lower proportion of extranodal lymphomatous involvement.

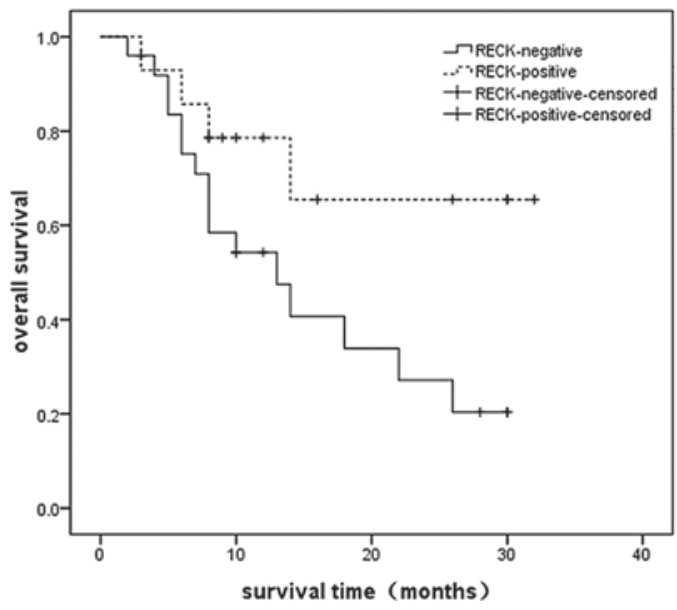

Figure 3. Kaplan-Meier analyses for overall survival for reversion-inducing cysteine-rich protein with Kazal motifs (RECK)-positive cases compared with $R E C K$-negative cases. The solid line represents negative staining, and the dotted line represents positive staining. The 3-year survival rate of the RECK-positive patients was significantly higher compared with that of the RECK-negative patients.

malignant tumors that share an poor prognosis. The cause of the poor survival outcome of patients with PTCL compared with patients with aggressive B-cell lymphomas remains largely unexplained. Possible reasons include the rarity of these disorders and their biological heterogeneity, which make them difficult to study. Moreover, the inclusion of only small proportions of PTCL patients in studies investigating therapies for aggressive B-cell lymphoma has not aided these therapeutic strategies. For the majority of PTCL subtypes, a poor outcome with a 5 -year overall survival of $\sim 30 \%$ is reported in the predominance of studies $(9,10,23-27)$. Previous studies have shown that the parameters that may be independent prognostic factors for survival in PTCL, excluding anaplastic large cell lymphoma (ALCL), include age $>60$ years, disseminated stage, LDH level higher than normal, performance status and a higher IPI and tumor score (10). However, the superiority of these parameters has not been well documented in subsequent studies (28). It may be necessary to investigate the molecular markers predicting the response to chemotherapy, the overall prognosis and the likelihood of extranodal lymphomatous involvement at diagnosis. This may also provide targets for the development of new therapeutic agents.
RECK, a novel MMP inhibitor, was first identified by Takahashi et al in the NIH3T3 cell line transfected with the $\mathrm{v}-\mathrm{Ki}$-Ras gene (12). The RECK gene encodes a $110 \mathrm{kDa}$ membrane-anchored glycoprotein that contains serine protease inhibitor-like domains and multiple epidermal growth factor-like repeats (12). Initially, RECK was believed to be a novel transformation suppressor gene, but it was later identified that $R E C K$ was able to inhibit the secretion and activity of three MMPs; MMP-2, MMP-9 and MTl-MMP. Numerous oncogenes, including ras, fos and $m y c$, downregulate the expression of $R E C K$, indicating that $R E C K$ may be a negatively-regulated target of oncogenes (29). A previous study reported that $R E C K$ is associated with angiogenesis and its appropriate expression inhibits the development of blood vessels (13). Studies have indicated that there is a positive correlation between RECK expression in tumors and the survival outcome of patients with other types of tumors, including hepatocellular carcinoma (15), pancreatic cancer (14), breast cancer (16) and non-small cell lung cancer (17). The correlation may therefore be a common feature among numerous tumors and this appears consistent with the previous findings showing that the prognosis for patients that were positive for the expression of RECK was better than for those who were negative.

In the present study, RECK expression in biopsy specimens and its prognostic significance in patients with PTCL was investigated. It was demonstrated that reduced RECK expression was a significant factor for predicting a poor prognosis. The clinicopathological analysis revealed that the expression of $R E C K$ was not notably correlated with the age, gender, pathological classification or tumor stage of the patients, but that it was associated with extranodal lymphomatous involvement and prognosis in PTCL. The results suggested that positive RECK expression was significantly associated with a lower proportion of extranodal lymphomatous involvement and a longer overall survival, although further studies are required in order to confirm this conclusion. In addition, clinicopathological factors were revealed, including RECK expression and response to chemotherapy, which may be useful prognostic determinants of favorable overall survival in patients with PTCL.

Numerous studies have suggested that the expression of $R E C K$ is associated with tumor metastasis and is useful as an informative prognostic indicator for several neoplastic diseases $(15-17,29)$. In the present study, it was revealed that the patients who were positive for the expression of RECK had less extranodal lymphomatous involvement and a longer overall survival; these results were consistent with those of previous reports. The 3-year overall survival rate of this group of patients was $46 \%$ and the median survival was 18 months. The 5-year survival rate of patients with PTCLs is reported as $\sim 30 \%$ in the literature $(9,10,23-27)$, which is consistent with the present study.

Certain limitations have been noted in the design of the present study. The study was an initial retrospective analysis of patients with a relatively small sample size, which meant that the study had limited statistical power and ultimately caused the data to generate a certain amount of deviation.

In conclusion, a significant correlation between RECK expression in PTCL and extranodal lymphomatous involvement of the patients was identified. A positive correlation between $R E C K$ expression and the survival rates of the patients was 
also observed. These data are consistent with the RECK model playing an active role in suppressing the malignant phenotypes of PTCL cells. Practically, RECK expression may be a good prognostic indicator in PTCL patients, and therapeutic strategies based on RECK or its mechanism of action may be of value in the treatment of this disease. Moreover, the clinical use of $R E C K$ as a prognostic indicator requires further evaluation.

\section{Acknowledgements}

The authors would like to thank Dr Jie Liu and Jing Xiong, Department of Pathology, Tongji Hospital, for the preparation of the histological sections and their excellent technical assistance.

\section{References}

1. Lennert $\mathrm{K}$ and Feller AC: The diagnosis of lymphoma. In: Histopathology of Non-Hodgkin's Lymphomas (Based on the Updated Kiel Classification). 2nd edition. Berlin, Springer-Verlag, pp1-6, 1992.

2. Harris NL, Jaffe ES, Stein H, Banks PM, Chan JK, Cleary ML, Delsol G, De Wolf-Peeters C, Falini B Gatter KC, et al: A revised European-American classification of lymphoid neoplasms: a proposal from the International Lymphoma Study Group. Blood 84: 1361-1392, 1994

3. Jaffe ES, Harris NL, Stein H and Vardiman JW: Pathology and genetics of tumours of haematopoetic and lymphphoid tissues. In: WHO Classification of Tumours. Kleihues P, Sobin LH (eds). Vol 3. 1st edition. Lyon, France, IARC Press, pp1-351, 2001.

4. Pileri S, Ralfkiaer E, Weisenburger D, et al: Peripheral T-cell lymphoma, not otherwise specified. In: WHO Classification of Tumors of Hematopoietic and Lymphoid Tissues. Swerdlow S, Campo E, Harris NL, et al (eds). 4th edition. Lyon, IARC; p429, 2008.

5. Vose J, Armitage $\mathrm{J}$ and Weisenburger D; International T-Cell Lymphoma Project: International peripheral T-cell and natural killer/T-cell lymphoma study: pathology findings and clinical outcomes. J Clin Oncol 26: 4124-4130, 2008.

6. Su IJ, Wang CH, Cheng AL, Chen YC, Hsieh HC, Chen CJ, Tien HF, Woei-Tsay, Huang SS, Hu CY, et al: Characterization of the spectrum of postthymic T-cell malignancies in Taiwan. A clinicopathologic study of HTLV-l-positive and HTLV-l-negative cases. Cancer 61: 2060-2070, 1988.

7. Takagi N, Nakamura S, Ueda R, Osada H, Obata Y, Kitoh K, Suchi T and Takahashi T: A phenotypic and genotypic study of three node-based, low-grade peripheral T-cell lymphomas: angioimmunoblastic lymphoma, T-zone lymphoma, and lymphoepithelioid lymphoma . Cancer 69: 2571-2582, 1992.

8. Nakamura S, Suchi T, Koshikaua T, Suzuki H, Oyama A, Kojima M, Motoori T,Ueda R and Takahashi T: Clinicopathologic study of 212 cases of peripheral T-cell lymphoma among the Japanese. Cancer 72: 1762-1772, 1993.

9. López-Guillermo A, Cid J, Salar A, López A, Montalbán C, Castrillo JM, González M, Ribera JM, Brunet S, García-Conde J, Fernández de Sevilla A, Bosch F and Montserrat E: Peripheral T-cell lymphomas: initial features, natural history, and prognostic factors in a series of 174 patients diagnosed according to the R.E.A.L. Classification. Ann Oncol 9: 849-855, 1998.

10. Gisselbrecht C, Gaulard P, Lepage E, Coiffier B, Brière J, Haioun C, Cazals-Hatem D, Bosly A, Xerri L, Tilly H, Berger F Bouhabdallah R and Diebold J: Prognostic significance of T-cell phenotype in aggressive non-Hodgkin's lymphomas. Groupe d'Etudes des Lymphomes de l'Adulte (GELA). Blood 92: 76-82, 1998.

11. No authors listed: Effect of age on the characteristics and clinical behavior of non-Hodgkin's lymphoma patients. The Non-Hodgkin's Lymphoma Classification Project. Ann Oncol 8: 973-978, 1997

12. Takahashi C, Sheng Z, Horan TP, Kitayama H, Maki M, Hitomi K, Kitaura Y, Takai S, Sasahara RM, Horimoto A, Ikawa Y, Ratzkin BJ, Arakawa T and Noda M: Regulation of matrix metalloproteinase- 9 and inhibition of tumor invasion by the membrane anchored glycoprotein RECK. Proc Natl Acad Sci USA 95: 13221-13226, 1998.
13. Oh J, Takahashi R, Kondo S, Mizoguchi A, Adachi E, Sasahara RM, Imamura Y, Kitayama H, Alexander DB, Ide C, Horan TP, Arakawa T, Yoshida H, Nishikawa S, Itoh Y, Seiki M, Itohara $\mathrm{S}$, Takahashi $\mathrm{C}$ and Noda $\mathrm{M}$ : The membrane-anchored MMP inhibitor RECK is a key regulator of extracellular matrix integrity and angiogenesis. Cell 107: 789-800, 2001.

14. Masui T, Doi R, Koshiba T, Fujimoto K, Tsuji S, Nakajima S, Koizumi M, Toyoda E, Tulachan S, Ito D, Kami K, Mori T, Wada M, Noda $M$ and Imamura M: RECK expression in pancreatic cancer: its correlation with lower invasiveness and better prognosis. Clin Cancer Res 9: 1779-1784, 2003.

15. Furumoto K, Arii S, Mori A, Furuyama H, Gorrin Rivas MJ, Nakao T, Isobe N, Murata T, Takahashi C, Noda M and Imamura M: RECK gene expression in hepatocellular carcinoma: correlation with invasion-related clinicopathological factors and its clinical significance. Reverse inducing - cysteine rich protein with Kazal motifs. Hepatology 33: 189-195, 2001.

16. Span PN, Sweep CG, Manders P, Beex LV, Leppert D and Lindberg RL: Matrix metalloproteinase inhibitor reversion-inducing cysteine-rich protein with Kazal motifs: a prognostic marker for good clinical outcome in human breast carcinoma. Cancer 97: 2710-2715, 2003.

17. Takenaka K, Ishikawa S, Kawano Y, Yanagihara K, Miyahara R, Otake Y, Morioka Y, Takahashi C, Noda M, Wada H and Tanaka F: Expression of a novel matrix metalloproteinase regulator, RECK, and its clinical significance in resected non-small cell lung cancer. Eur J Cancer 40: 1617-1623, 2004.

18. Takeuchi T, Hisanaga M, Nagao M, Ikeda N, Fujii H, Koyama F, Mukogawa T, Matsumoto H, Kondo S, Takahashi C, Noda M and Nakajima Y: The membrane-anchored matrix metalloproteinase (MMP) regulator RECK in combination with MMP-9 serves as an informative prognostic indicator for colorectal cancer. Clin Cancer Res 10: 5572-5579, 2004.

19. Li Y, Zhang Y and Zheng Q: Expression of RECK gene and MMP-9 in hilar cholangiocarcinoma and its clinical significance. J Huazhong Univ Sci Technolog Med Sci 25: 552-554, 2005.

20. Harris NL, JaffeES, Diebold J,Flandrin G, Muller-Hermelink HK, Vardiman J, Lister TA and Bloomfield CD: The World Health Organization classification of neoplastic diseaes of the hematopietic and lymphoid tissues. Report of the Clinical Advisor Committee meeting, Airlie House, Virginia, November 1997. Ann Oncol 10: 1419-1432, 1999.

21. No author listed: A predictive model for aggressive non-Hodgkin's lymphoma. The International Non-Hodgkin's Lymphoma Prognostic Factors Project. N Engl J Med 329: 987-994, 1993.

22. Friedrichs K, Gluba S, Eidtmann H and Jonat W: Overexpression of p53 and prognosis in breast cancer. Cancer 72: 3641-3647, 1993.

23. Melnyk A, Rodriguez A, Pugh WC and Cabannillas F: Evaluation of the Revised European-American Lymphoma classification confirms the clinical relevance of immunophenotype in 560 cases of aggressive non-Hodgkin's lymphoma. Blood 89: 4514-4520, 1997 .

24. Savage KJ, Chhanabhai M, Gascoyne RD and Connors JM: Characterization of peripheral T-cell lymphomas in a single North American institution by the WHO classification. Ann Oncol 15: 1467-1475, 2004.

25. Gallamini A, Stelitano C, Calvi R, Bellei M, Mattei D, Vitolo U, Morabito F, Martelli M, Brusamolino E, Iannitto E, Zaja F, Cortelazzo S, Rigacci L, Devizzi L, Todeschini G, Santini G, Brugiatelli $\mathrm{M}$ and Federico M; Intergruppo Italiano Linfomi: Peripheral T-cell lymphoma unspecified (PTCL-U): a new prognostic model from a retrospective multicentric clinical study. Blood 103: 2474-2479, 2004

26. Cheung MM, Chan JK, Lau WH, Foo W, Chan PT, Ng CS and Ngan RK: Primary non-Hodgkin's lymphoma of the nose and nasopharynx: clinical features, tumor immunophenotype, and treatment outcome in 113 patients. J Clin Oncol 16: 70-77, 1998.

27. Chim CS, Ma SY, Au WY, Choy C, Lie AK, Liang R, Yau CC and Kwong YL: Primary nasal natural killer cell lymphoma: long-term treatment outcome and relationship with the International Prognostic Index. Blood 103: 216-221, 2004.

28. Piccaluga PP, Agostinelli C, Gazzola A, Mannu C, Bacci F, Sabattini E and Pileri SA: Prognostic markers in peripheral T-cell lymphoma. Curr Hematol Malig Rep 5: 222-228, 2010.

29. Sasahara RM, Takahashi $C$ and Noda M: Involvement of the Sp1 site in ras-mediated downregulation of the RECK metastasis suppressor gene. Biochem Biophys Res Commun 264: 668-675, 1999. 